\title{
THE CASE FOR LOW-COST, PERSONALIZED VISUALIZATION FOR ENHANCING NATURAL HAZARD PREPAREDNESS
}

\author{
Peter Gmelch ${ }^{1}$, Raul Lejano ${ }^{1}$, Evan O’Keeffe ${ }^{2}$, Debra F. Laefer ${ }^{2}$, Cady Drell $^{1}$, Michela Bertolotto ${ }^{3}$, Ulrich Ofterdinger ${ }^{4}$, Jennifer \\ McKinley $^{4}$ \\ ${ }^{1}$ Steinhardt School of Culture, Education, and Human Development, East Bldg, 239 Greene Street, Floor 6, NY, NY - (plg275, \\ lejano, ced478)@nyu.edu \\ ${ }^{2}$ Center for Urban Science and Progress and the Department of Civil and Urban Engineering, Tandon School of Engineering, New \\ York University, 370 Jay St., 1301C, Brooklyn, NY - (eo52, debra.laefer)@nyu.edu \\ ${ }^{3}$ School of Computer Science, University College Dublin, Belfield, Dublin 4, Ireland - michela.bertolotto@ucd.ie \\ ${ }^{4}$ School of Natural and Built Environment, Queen's University, Stranmillis Rd, Belfast, BT9 5AG UK - (u.ofterdinger,
} j.mckinley)@qub.ac.uk

KEY WORDS: Imagery, Augmented Reality, Virtual Reality, Flood, Risk, Communication

\begin{abstract}
:
Each year, lives are needlessly lost to floods due to residents failing to heed evacuation advisories. Risk communication research suggests that flood warnings need to be more vivid, contextualized, and visualizable, in order to engage the message recipient. This paper makes the case for the development of a low-cost augmented reality tool that enables individuals to visualize, at close range and in three-dimension, their homes, schools, and places of work and worship subjected to flooding (modeled upon a series of federally expected flood hazard levels). This paper also introduces initial tool development in this area and the related data input stream.
\end{abstract}

\section{INTRODUCTION}

Annually thousands of people fail to evacuate from water hazard events. As will be discussed, a number of cognitive models support the proposition that augmented/virtual reality (AR/VR) could help overcome persistent cognitive roadblocks to effective risk communication and subsequent evacuation actions. Virtual reality enables the user to explore a virtual representation of a specific space (real or synthetic). Augmented reality layers simulated features on top of actual scenes. In this paper, these sets of technologies will be treated as one under the term AR/VR. Thus, this paper introduces the related literature and initial efforts in related tool development in AR/VR for communicating, and preparing for, the risks of extreme weather events such as tropical cyclones, floods, and storm surges.

\section{CONCEPTUAL JUSTIFICATIONS FOR THE USE OF AR/VR}

Risk preparedness is a factor of what scholars sometimes refer to as experiential processing (i.e., the extent to which previous events have primed the public to understand the nature of risk (Marx et al., 2007). This is directly related to an individual's or group's memories of past events (Vasileiadou and Botzen, 2014) and, less directly, related to institutional memory, which pertains to how events, even those in the distant past, are reflected in customs or local institutions that have become embedded in a place (Sharma et al., 2013). Problems arise when the risks are of such nature or magnitude that the populace has never experienced anything like it. There is mounting evidence that climate change is creating risk scenarios of just this sort, as climate models suggest that extreme weather events (e.g., tropical cyclones) will increase in frequency and severity in the coming decades (Emanuel, 2013; Grinsted et al., 2013). Thus, the challenge is that people will not have a good idea of what such an event would be like, but also that the prospect of such an event happening to them will seem less likely.
As AR/VR can be thought of as a means for creating the sensation that the user is somewhere where they are not (Virtual Reality Society, 2017), such technology could play a role in making an event easier to imagine and picture is a compelling prospect. With AR/VR visualization, a disaster event may also become more realistic, especially if the technology supports vivid, detailed imagery. For example, Haynes, Hehl-Lange, and Lange (2018), developed a mobile augmented reality app that allows one to select a setting and, using a smartphone, simulate a pre-specified flood onto the scene. Lieske (2012) discusses how such visualization tools make up for, or complement, one's understanding of the severity of a risk. However, it is an open question whether such visualization aids motivate individuals to act, since the person's personal threshold for action has to be met, along with a perception that one's actions can be effective (Lieske, 2012).

These notions are corroborated by various cognitive models, such as the elaboration-likelihood model (ELM) [Petty and Cacioppo 1984, 1986]. ELM proposes a theory about processes by which a person receives a message from another and how and why such a message is internalized by the person and influences behavior. The likelihood that a person can plan for an event in advance is increased to the extent that the risk information is perceived as self-relevant and the consequences of the event perceived as threatening. AR/VR can, conceptually, aid in this respect, especially if an event like a flood is visualized at a person's specific locale (increasing selfrelevance) and makes the magnitude of a large event more realistic (increasing consequentiality).

AR/VR may enhance risk communication in yet another way, which is to increase a person's perception of both the ability to act and the efficacy of any potential risk-reductive action, as proposed by the Theory of Planned Behavior (Ajzen, 1991). Conceivably, viewing a realistic rendering of one's own home 
under flood conditions locale may allow the person to more explicitly imagine how to react in such a situation, which can likewise increase the perceived efficacy of such action. By increasing the degree of realism of one's mental model or imagery of the hazard scenario, the consequences of the event, and any risk-reductive action might likewise be more tangible.

Lastly, the Relational Theory of Risk Communication suggests that AR/VR might help in transforming community residents from passive recipients of technical information to active agents who are more willing to act upon their situation (Lejano et al., 2018; Lejano et al., 2020). Again, the qualities of the AR/VR interface could be an important element. If the user could move around a simulated environment in different ways, it may also increase the person's sense of empowerment.

This suggests that the quality (i.e., the degree of resolution and detail) of the simulated image may be key to enhancing the above effects. The simulations should also be of actual places ideally, near the user's home or place of work. The ability to toggle or move through the scene (simulating actual movement) may enhance the tangible aspects of the simulation.

Research in environmental psychology routinely demonstrates that people's perception of their environment fosters their ability to behave with improved cognition and stronger emotion. These stronger connections to their environment can also change the way they behave and interact in social environments (Russel et al., 1982). With AR/VR, the user can trick the mind, immerse the senses in a different way, and provide context to a place without the need of being physically present. This utility is being explored in many areas of science, including ecology, urban systems, environment, and climate. To create realistic and immersive experiences, several components are required. Stereoscopic displays are a preliminary and basic component and simply provide a 3D visualizer for the user, typically through a head mounted display. In order to replicate the sensation of moving one's body and observe the surroundings, some sort of motion tracking hardware is required. Something like a gyroscope or accelerometer allows the software to pick up on the user's body motion. Input devices, such as joysticks or keyboards, can let the user navigate the virtual space through gestures and movement. Lastly a visual platform is required to run the application (Velev and Zlateva, 2017).

The literature is still sparse regarding how qualities of the AR/VR images and interfaces affect the effectiveness of the simulation and through what cognitive pathways these interfaces work to enhance risk perception and readiness-to-act.

\section{BACKGROUND: THE EVOLUTION OF AR/VR}

AR/VR is one of the many modern technological breakthroughs that has surged in popularity over the past decade. Although there are many applications for this technology, the most commonly known is its use in conjunction with video games. Consoles like the Sony Playstation created early iterations of consumer grade virtual reality headsets, such as the company's namesake VR headset released in 2016, selling over 4.2 million units globally as of March 2019 (Shuman, 2019). Like other gaming studios, Sony entered the consumer level VR market following the early success of Oculus. Oculus VR raised nearly \$2.5 million dollars through a Kickstarter crowdfunding campaign in 2012 for its first generation device the Oculus Rift. In March 2014, Facebook purchased Oculus for $\$ 2$ billion (Orland, 2014). While the 2010s marked the heyday for AR/VR, attempts at virtual reality can be traced back as early as the 1830s. In 1838, scientists such as Charles Wheatstone and David Brewster contributed to the development of a stereoscope. The original design and construction of this device was later used to make the View-Master stereoscope, where users could look at images through a viewfinder. Subsequently, Google used this design to make Google Cardboard, a low budget system that has a smartphone mount, providing low cost VR accessibility to users (Virtual Reality Society, 2017).

\subsection{Applications of AR/VR to Emergency Preparedness}

In 2005, Beckett and Shaffer explored the use of gaming environments (in their case SimsWorld) and its effects on informed city planning. Their paper argues that the use of virtual models, through video games and augmented reality, can provide students with informed representations for problem solving in complex environments. The idea of virtual reality providing experiential problem-solving activities is actively being explored in disaster preparedness and emergency response. For example, Schuurink and Toet (2010) employed virtual models by using the game Second Life, conceptually similar to SimsWorld, to have participants navigate evacuation routes in disaster situations. Although their experimental group was small $(n=22)$, their study found that the participant's viewing perspective aided their search and evacuation missions within the module.

Bernardes et al. (2015) explained how AR/VR can train emergency workers (and the public) by simulating the three phases of an emergency situation: risk perception (i.e., recognizing contextual cues for action), movement/behavior (i.e., carrying out risk-avoidance or mitigating actions), and post-movement (i.e., steps proceeding after initial evacuation or other response).

Beyond the applications of random study participants, AR/VR is being used to train medical personnel, from everyday tasks to mass casualty events, and can provide a safe learning and practice space for personnel in this field. Farra et al. (2015) explored AR/VR and its role in situated cognition. When the learner enters an augmented reality, they experience embeddedness, extension, and embodiment (Farra et al., 2015). With practice and repetition, the learner will have an increased understanding of the simulation, hopefully translating to better performance in a real disaster scenario. Farra et al. (2015) used AR/VR to have nursing students undergo disaster training, with half of their group using web-based modules instead. The participants found the AR/VR experience to be more engaging and provided a realistic method of practice as opposed to watching informational PowerPoints and videos via web-based training.

Andreatta et al. (2010) explored the differences in efficacy between AR/VR and standardized patient drills when providing triage during mass casualty incidents. While they did not find significant differences between the two, AR/VR seemed to be favored, as it was cost-effective compared to using live volunteers in disaster drills. The feasibility and repeatability of AR/VR makes it a realistic alternative to live drills and may lead to better results in live drills when used in tandem. Technologies like this aim to ameliorate the negative impacts that cognitive dissonance can have during mass casualty events. This dissonance can result from sensational overload and is likely to negatively impact honed skill sets in emergency medical personnel (Andreatta et al., 2010). Applied contexts such as AR/VR serve as better alternatives to non-applied contexts, such as web-based or lecture formatted training that 
has been explored in other research in emergency preparedness. $\mathrm{AR} / \mathrm{VR}$ is growing in popularity in the educational sphere in a multitude of disciplines. In another case, AR/VR was used to train obstetrics teams, resulting in significantly less errors in real time applications (Merién et al., 2011).

In the case of the United States and disaster and emergency preparedness, several government agencies are taking advantage of AR/VR technology training. For example, the New York City Office of Emergency Management and Los Angeles Police Department are actively using simulation systems to train staff on emergency operation, navigating urban environments, and communication with colleagues during these events (Hsu et al., 2013). Recent terrorist events and natural disasters in the past few decades have prompted municipalities to improve their staff's preparedness, and AR/VR technology provides the potential for an efficient and cost sensible training method. In the case of natural disasters and their increased occurrences due to climate crises, there is a growing demand for efficacious AR/VR training programs that will help not just first responders, but citizens who have a rising susceptibility to natural disasters as the climate crisis worsens.

\subsection{Application of VR to Risk Communication}

Although one cannot replace first-hand experiences of natural hazards, it is thought that, as the simulation is credible, AR/VR may prime the public to better perceive risks and plan for them (Mitchell and Cutter, 1997; Basic et al., 2003; Maidl and Buchecker, 2014; Havenith et al., 2019) ${ }^{1}$.

Best practices of crisis and risk communication rely on initial notifications commencing prior to the event. The message's specificity, clarity, and certainty determine how effective it is (Markwart et al., 2019). It is then up to the citizen to make a rational decision based on the magnitude of risk associated with the event. Modes of risk communication can vary from generalized, regional warnings (e.g., "floods ranging from 1 to 3 feet expected on the east coast") to context-specific ones ("2 foot storm surge along seafront between 5th St. and 8th St."). Risk messages also vary depending on mode of expression, the simplest being plain text (i.e., words on paper or on a screen). Often, text will be supplemented with graphic aids such as maps which give two-dimensional place-specific hazard information. Flood and storm surge maps have been shown to aid the public's understanding of the risk, though people display differing degrees of comfort/skill at interpreting maps (Morrow et al., 2015). In this article, we explore the possibilities of 3D flood representations for improving viewer comprehension even further.

However, if the individual has no prior experience with certain types of disasters or environmental hazards, there is no experience from which to draw. AR/VR training aims to provide experiences to draw from that work in tandem with warning messages, hopefully leading to rational decision making and increased safety of communities. Markwart et al. (2019) tested the efficacy of warning messages through AR/VR by putting participants in virtual storms and having them navigate to shelters following the message being received. All but 1 of their 31 participants made it to a shelter within a safe amount of time. Moreover, participants who received the warning through the app found an escape route more quickly

${ }^{1}$ https://games4sustainability.org/gamepedia/forest-at-risk/ than the control group (Markwart et al., 2019). Though receiving warning messages during storm events is a rudimentary aspect of overall risk communication and best safety practices, this research successfully illustrates the importance of comprehensive communication lines between public authorities and the community in order to ensure safety. Aside from the utility of $\mathrm{AR} / \mathrm{VR}$ as a medium for training personnel and community members, virtual environments are useful for observing communities and understanding their susceptibility and need for future adaptations within their social environment or infrastructure. An example of using this technology to generate input to government planning risk management activities to mitigate damage was done by Avagyan et al. (2018) for the Ministry of Emergency Situations of Armenia. That study was undertaken to evaluate the relevant physical, social, and economic components in Armenia to better understand the population's coping and adaptive capacity, as well as its general vulnerability. Armenia is prone to earthquakes, landslides, and an array of other hazardous natural processes such as strong wind and drought. Using a simulated environment, spatial evaluations were conducted to collect data on hazard assessment for various environmental risks. A vulnerability index was then applied to each region, as a composite of physical, social, and economic risk and certain communities were targeted as being especially vulnerable. Similarly, Wang et al. (2019) simulated the flooding levels of a Chinese city with and without additional infrastructure.

The research team is planning on translating these visualizations to AR/VR headsets to share with stakeholders and community members to encourage the development of crucial infrastructure improvements by showing how such investments can mitigate flooding (Wang et al., 2019).

With a successful track record in the training of equipment operators and medical personnel, AR/VR would appear to hold the potential to ameliorate some of the impacts of natural disasters and the burden placed on first responders by better educating communities and providing community members safe immersions into disaster scenarios, allowing direct perception of these environments more effectively than other methods (Hu et al., 2018).

Studies in the mid to late 2000s, such as Beckett and Shaffer (2005) and Schuurink and Toet (2010) utilized GIS or even video games, such as Sims or Second Life, to test risk assessment workshops. These studies were useful and found success in teaching participants about risk preparedness, how to navigate escape routes or hazardous obstacles during disaster scenarios, and visualize the impact of natural disasters. Arguably AR/VR of impacted areas could provide localized context to these events and influence behavior and attitudes towards disaster preparedness. Older versions of flood maps, including physical mediums and GIS displays, are not readily understandable to the general public, who generally have difficulty deriving meaning from them (Macchione et al., 2019; Hagemeier-Klose and Wagner, 2009). To the extent that a 3D visualization more closely resembles the real situation, it has the possibility of overcoming limitations posed by 2D maps to those for whom the latter are too abstract or non-realistic (Lieske, 2012).

Changing perceptions can serve as a keystone solution for shifting the attention of the public eye. Solinkska-Nowak et al. (2018) compiled an overview on risk management through virtual reality games which provide training for different scenarios. One visualization called VR for a New Climate had 
participants operate a variety of devices and perform functions during a flood disaster scenario, spanning from activating alarm bells or loading relief kits for transport. Other examples include Forest@Risk which emphasizes the idea of the "tragedy of the commons" and the impacts that the climate crisis will have on natural resources. Applications of this game in workshops showed interesting results as the game provides communication lines between players which leads to complex decision making and cooperation in order to conserve natural resources for a community. The social dimension that activity-based games or interactive AR/VR workshops possess are one of the utility's most potent advantages when creating or improving the way communities handle natural disasters and build on their resiliency. Not only do these activities provide tangible lessons within themselves, but a lot of learning happens after the fact during debriefing sessions (Crookall 2010) where participants are able to discuss the pros and cons of the workshop or scenario within the game model, allowing them to repeat the experiment and further build on this social component and its relation to risk communication and preparedness.

Evans et al. (2014) found efficacy in their experiment when they presented 3D visualizations to the community of Exeter, England during a 50 $0^{\text {th }}$ anniversary commemoration of historic flooding in 1960. Participants in their experiment described the visualizations as a wake-up call and were reminded that though modern infrastructure may provide some protection, increasing intensity of rainfall and storm surge due to climate crises may make this problem closer to home than previously anticipated. One notable point from the participants was that the realization of flood damage to local landmarks was "chilling and sobering". Responses like these are easy to derive from experiments that utilize VR technology since the visualizations are easy to interpret compared to older versions of $3 \mathrm{D}$ modeling and enhanced mapping, especially when technology such as drones and LIDAR data are utilized to construct highly detailed replicas of familiar locales. Two years after Evans et al. (2014) conducted their research, high-flow flooding occurred in the Exeter region, and the UK's Environment Agency reported heightened awareness of protocol, which the authors attributed to flood visualization workshops.

Macchione et al. (2019) used a similar approach in Cosenza, Italy which has been prone to flooding as early as the 1590s and as recent as the 1950s. This time span provided an opportunity for the researchers as they were able to better understand the perception of participants who had experienced flooding in the 1950 s, and the younger generations who have not experienced any. Through vivid visuals, Macchione et al. (2019) were able to contextualize the risk and substituted the visuals for the experience of flooding that older generations had. A portion of this workshop focused on emergency preparation and participants were able to focus on risk communication within the community, such as when certain roads were impassable and climbing to rooftops of buildings for safety located throughout the city.

The results from experiments like these suggest that effective and impactful virtual reality programs should be tailored to local areas to provide a social component to the participants, especially if the given area is prone to flood risk and storm surge. Enhanced virtual and augmented reality technologies provide researchers with opportunities to create immersive environments that can lessen the disconnect that many citizens have from the consequences of the climate crisis, especially those who have not had experience with natural disasters and are now facing potential scenarios due to worsening climate conditions. Aside from community members, policy makers and public stakeholders are benefiting from the use of VR technology. An example of the initial development of such a tool is next explained.

\section{TOOL INTRODUCTION}

\subsection{Overview statement of the goals of the technology}

The primary goal of the UrbanARK system was to create an inexpensive means to simulate $3 \mathrm{D}$ environments with flood inundation data to better contextualize what particular flooding models are trying to convey. Using commercially off-the-shelf (COTS) hardware and open source packages increases the likelihood that this would be accessible to more communities than development of an entirely new piece of hardware. As such the UrbanARK tool has the user wear a cheap readily available/easy to build AR/VR viewer for a smart mobile phone device. The smart phone renders the $3 \mathrm{D}$ environment for the user, projected through a set of lenses, which creates the $3 \mathrm{D}$ effect. To be operational the smart phone must be equipped with a set of commonly incorporated sensors. These include an accelerometer, a gyroscope, and a magnetometer. Together these convey user location within the space and head orientation to simulate the heads movements through the 3D virtual environment. The work file is shown in Figure 1.

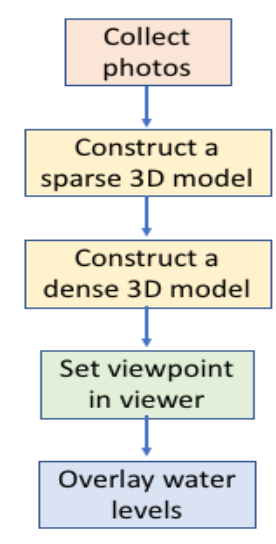

Figure 1. Workflow Overview

\subsection{Input data}

The input data consist of a set of images of a point of interest captured using a COTS camera digital single lens reflex (DSLR) or mobile phone camera, or an inexpensive Unmanned Aerial Vehicle with an inbuilt or custom mounted camera. Using a device enabled with a global positioning system (GPS) helps scale the environment automatically, so that buildings, roads, and other easily recognizable features are at a real-world scale during the creation of the 3D model. Preferably, the GPS data are contained within the Exchangeable Image File format (EXIF) meta-data of the image file itself, as is readily available in many smartphones. This is helpful, especially for larger 3D model renders with limited computing power, as the images can be clustered and processed on any available hardware, and then easily joined with other clusters as the clusters are geo-rectified to a specific GPS scale space (e.g. WGS84 or UTM in meters).

\subsection{Model Generation and Software}

Model generation is handled by third party software packages. To allow any community to build a model for viewing, the 
openMVG (Moulon et al., 2016) was selected. This software framework is fully open source and contains software plugins to help data generated from other 3D reconstruction or densification packages. openMVG (Moulon et al., 2016) can be used with simple Python language scripting in the command terminal or Regard3D (Regard3D, 2020), a graphical user interface being built to support openMVG (Moulon et al., 2016). The model generation works by first organizing the images to be used in the reconstruction by putting them into a folder. The openMVG_main_SfMInit_ImageListing then looks at the image directory and creates the initial openMVG structure for the framework. This is followed by image feature extraction (identifying interesting features within the images) using openMVG_main_ComputeFeatures. If there are a large number of images, images are clustered based on GPS position data using openMVG_main_ListMatchingPairs. After this there is the image feature descriptor matching stage using openMVG_main_ComputeMatches. This stage requires some experimentation by the user, to set the matching ratio. If the matching ratio is too high, sufficient points may not exist to do the reconstruction. If the matching ratio is too low, there may be a lot of noise. Once the matching is complete, then openMVG main_GlobalSfM is used to generate the sparse 3D point cloud. This sparse 3D model shows whether the image descriptor matching ratio was appropriate. If the model is usable, the model is then prepared for densification using the Multiple View Environment (MVE) (Fuhrmann et al., 2014) package.

Densification is done by first using the framework converter openMVG_main_openMVG2MVE2 in the openMVG package. This generates the file structure for (Fuhrmann et al., 2014). The next step is to start the densification using the MVE (Fuhrmann et al., 2014) dmrecon program, which estimates depth (distance from camera) for each pixel in each image. The last step is the dense map merging using MVE's scene2pset program. This takes all the dense depth maps and uses them to project the pixels from the images into a $3 \mathrm{D}$ scale space. The output from this is a dense point cloud generally in the PLY format (Turk, 1994).

Now that a 3D point cloud model has been generated, the 3D model viewer will need to be generated. For the 3D rendering Potree (Schuetz et al., 2020a) and Three.js (Cabello et al., 2020) are used in the browser to render the $3 \mathrm{D}$ model and flood inundation information in AR/VR. The VR effect is created by using the Three.js StereoEffect renderer. PotreeConverter (Schuetz et al., 2020b) is used to convert the data from its point cloud format into the Potree native Octree format. By doing this, Potree can generate the points that should be viewed into a Level Of Detail pyramid (LOD pyramid) that optimizes the rendering by only showing close points in full detail, and rendering fewer points at locations that are further away. This allows large models to be shown without the need to have expensive hardware to view them.

Now that the 3D environment can be viewed, the next step is to add the flood model data (Fig. 2). The first step is setting a reasonable height of the AR/VR viewers viewpoint. For this, a simple statistical average height of a person in the United States was used $(161.5 \mathrm{~cm}$ for females $+175.3 \mathrm{~cm}$ for males $=168.4 \mathrm{~cm}$ or 5 feet and 6.2992 inches). The height is then set in Potree by taking the height of the point cloud floor where the viewpoint is and adding $168.4 \mathrm{~cm}$ to it (the model scale space is in metric). Future applications would allow for different points of view and perspectives specific to individual users (e.g. children, people with visual impairments).

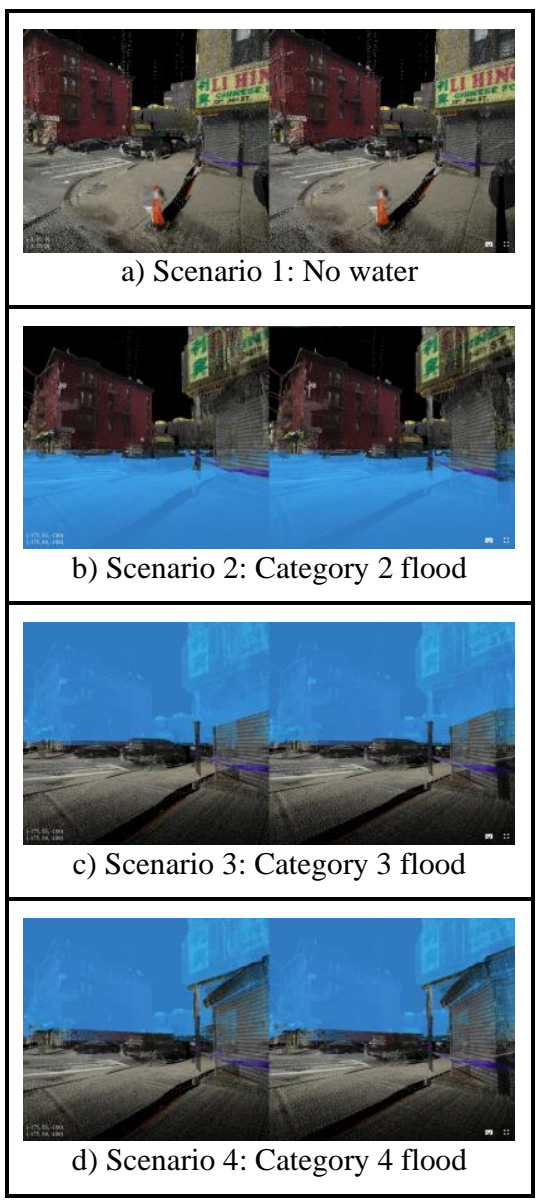

Figure 2. Viewer flood levels

The last step is setting the flood level within the model. This was generated by looking at the Federal Emergency Management Agency (FEMA, 2020) flooding maps. The spatial extent likely to be covered by a specific category of flooding is mapped in the 3D space. This space is then occupied by a polygon (Turk 1994). The flooding characteristic is created by mapping the category level to the z-height value of the polygon. If the entire scene is affected, then a cube is mapped across the entirety of the scene and then the same height designator is used. The height of the polygon or cube is set to that of the ground level of the point cloud.

Next, a timer is created in JavaScript that modifies the height of the polygon or cube to increase/rise to a particular FEMA (FEMA, 2020) map flood level (Figure 2). A texture can be applied to the polygon/cube for water, or a simple colour can be used to make the polygon or cube blue for the water level. The prototype system was built using 4 different scenarios. First is the $3 \mathrm{D}$ model with no flooding. The second scenario is the 3D model with category 2 flood levels. The third scenario is the $3 \mathrm{D}$ model with category 3 flood levels. The final scenario is the 3D model with category 4 flood levels. Once the final scenario has been shown, the system then loops back around to the first scenario. By using Three.js (Cabello et al., 2020), the user can press $\mathrm{w}, \mathrm{s}, \mathrm{a}, \mathrm{d}$ on the keyboard to move forward, back, left and right in the $3 \mathrm{D}$ environment. 


\subsection{Capabilities}

To promote wide adoption of UrbanARK as a flood risk communication tool, the entire system is open source, and the point cloud can be scaled to suit the processing power of the smartphone device being used. The system is compatible with higher end AR/VR equipment such as Oculus (Oculus, 2020) or HTC (HTC VIVE. 2020) headsets but is designed more for midrange and better smartphones. The AR/VR headset enables a full, 360-degree 3D AR/VR environment (Figure 3).

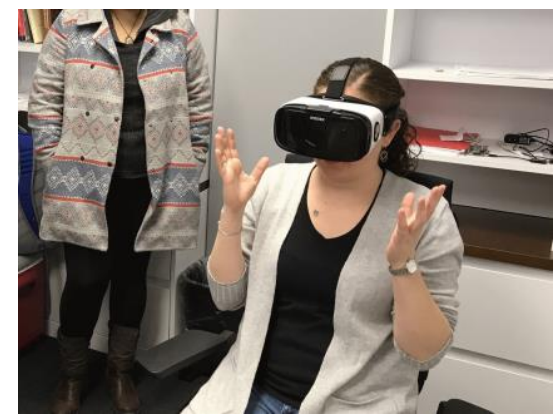

a) User with headset on

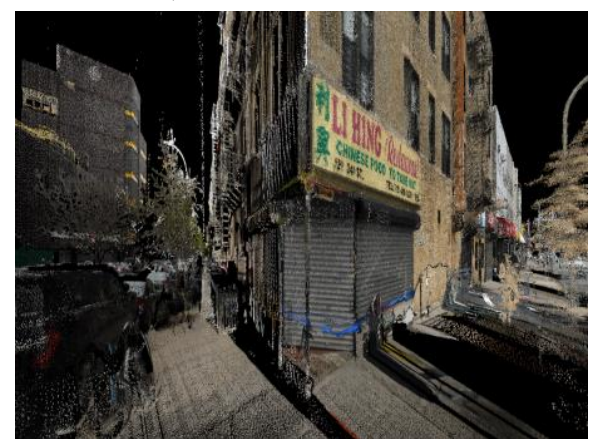

b) Scene visible within viewer

Figure 3. Viewer in use.

\section{CONCLUSIONS}

This system is compatible with any web browser that is webGL (Khronos Group Inc., 2020) 1.0 compatible. Future envisioned capabilities will allow users to walk around the 3D VR environment. Such additional features could permit users to test evacuation routes. While the alpha version of this AR/VR tool is ready for testing, the current COVID-19 situation prevents that. In the interim, the development team has been working on an online version.

There has been increasing use of $\mathrm{AR} / \mathrm{VR}$ and 3D visualization tools for risk communication and emergency preparedness. However, deeper research on this is lacking. To date, little work has been done as to what features or qualities of the visualization tool are more effective in hazard risk communication. Specifically, there is inadequate work on what cognitive pathways (increased consequentiality, enhanced vividness, affordance of individual agency, etc.) are triggered by use of these tools. There is also need for research on collaborative forums (e.g., PAR, scenario building, etc.) for community engagement. The low-cost UrbanARK AR/VR flood simulation tool may serve as a means to understanding some of these deeper issues.

\section{ACKNOWLEDGEMENTS}

Funding provided by the U.S. National Science Foundation (Award 1826134), Northern Ireland Trust (Award R3078NBE), and Science Foundation Ireland (Award 17/US/3450).

\section{REFERENCES}

Andreatta, P. B., Maslowski, E., Petty, S., Shim, W., Marsh, M., Hall, T., Stern, S., Frankel, J., 2010: Virtual Reality Triage Training Provides a Viable Solution for Disasterpreparedness. Academic Emergency Medicine, 17(8), 870-876. doi.org/10.1111/j.1553-2712.2010.00728.x.

Avagyan, A., Manandyan, H., Arakelyan, A., Piloyan, A., 2018: Toward a disaster risk assessment and mapping in the virtual geographic environment of Armenia. Natural Hazards, 92(1), 283-309. doi.org/10.1007/s11069-018-3208-0.

Ajzen, I., 1991: The theory of planned behavior. Organizational Behavior and Human Decision Processes, 50(2), 179-211. doi.org/10.1016/0749-5978(91)90020-T.

Beckett, K. L., Shaffer, D. W., 2005: Augmented by Reality: The pedagogical praxis of urban planning as a pathway to ecological thinking. Journal of Educational Computing Research, 33(1), 31-52. doi.org/10.2190/d5yq-mmw6-v0fr-rnjq.

Basic, F., Cartwright, W., Handmer, J., 2003: Geographic visualization tools for communicating the risk of floods. In Proceedings of the 21st International Cartographic Conference, 2033-2044. Durban, South Africa: International Cartographic Association.

Bernardes, S. M. F., Rebelo, F., Vilar, E., Noriega, P., Borges, T., 2015: Methodological approaches for use virtual reality to develop emergency evacuation simulations for training, in emergency situations. Procedia Manufacturing, 3, 6313-6320. doi.org/10.1016/j.promfg.2015.07.946.

Cabello, R., and others, 2020: three.js. GitHub. https://github.com/mrdoob/three.js/.

Crookall, D., 2010: Serious games, debriefing, and simulation/gaming as a discipline. Simulation and Gaming, 41(6), 898-920. doi.org/10.1177/1046878110390784.

Emanuel, K. A., 2013: Downscaling CMIP5 climate models shows increased tropical cyclone activity over the 21 st century. Proceedings of the National Academy of Sciences of the United States of America, 110(30), 12219-12224. doi.org/10.1073/pnas.1301293110.

Evans, S. Y., Todd, M., Baines, I., Hunt, T., Morrison, G., 2014: Communicating flood risk through three-dimensional visualization. Proceedings of the Institution of Civil Engineers Civil Engineering, 167(5), 48-55. doi.org/10.1680/cien.13.00020.

Hagemeir-Klose, M., Wagner, K., 2009: Evaluation of flood hazard maps in print and web mapping services as information tools in flood risk communication. Natural Hazard and Earth System Sciences, 9(2), 563-574. doi.org/10.5194/nhess-9-5632009. 
Farra, S. L., Miller, E. T., Hodgson, E., 2015: Virtual reality disaster training: Translation to practice. Nurse Education in Practice, 15(1), 53-57. doi.org/10.1016/j.nepr.2013.08.017.

Federal Emergency Management Agency, 2020. Home | FEMA.gov. https://www.fema.gov/

Fuhrmann, S., Langguth, F., Goesele, M., 2014: In Proceedings of the Eurographics Workshop on Graphics and Cultural Heritage, 11-18. Darmstadt, Germany: Eurographics Association.

Grinsted, A., J. C. Moore, and Jevrejeva, S., 2013: Projected Atlantic hurricane surge threat from rising temperatures. Proceedings of the National Academy of Sciences of the United States of America., 110(14), 5369-5373. doi.org/10.1073/pnas.1209980110.

Havenith, H.-B., Cerfontaine, P., Mreyen, A.-S., 2019: How virtual reality can help visualise and assess geohazards, International Journal of Digital Earth, 12(2), 173-189. doi.org/10.1080/17538947.2017.1365960.

Haynes, P., Hehl-Lange, S., \& Lange, E., 2018. Mobile augmented reality for flood visualisation. Environmental modelling \& software, 109, 380-389.

Hsu, E. B., Li, Y., Bayram, J. D., Levinson, D., Yang, S., Monahan, C., 2013: State of Virtual Reality Based Disaster Preparedness and Response Training. PLOS Currents, 1. doi.org/10.1371/currents.dis.1ea2b2e71237d5337fa53982a38b2 aff.

HTC VIVE, 2020: VIVE ${ }^{\mathrm{Tм}}$ | Discover Virtual Reality Beyond Imagination. https://www.vive.com/eu/.

Hu, Y., Zhu, J., Li, W., Zhang, Y., Zhu, Q., Qi, H., . . Zhang, P., 2018: Construction and Optimization of Three-Dimensional Disaster Scenes within Mobile Virtual Reality. ISPRS International Journal of Geo-Information, 7(6), 215. doi.org/10.3390/ijgi7060215.

Khronos Group Inc., 2020: Khronos royalty-free open standards for 3D graphics, Virtual and Augmented Reality, Parallel Computing, Machine Learning, and Vision Processing. WebGL. https://www.khronos.org/.

Lejano, R. P., Casas Jr, E. V., Montes, R. B., Lengwa, L. P., 2018: Weather, climate, and narrative: a relational model for democratizing risk communication. Weather, climate, and society, 10(3), 579-594. doi.org/10.1175/WCAS-D-17-0050.1.

Lejano, R. P., Rahman, M. S., Kabir, L., 2020: Risk

Communication for Empowerment: Interventions in a Rohingya Refugee Settlement. Risk Analysis. doi.org/10.1111/risa.13541. Lieske, D. J., 2012: Towards a framework for designing spatial and non-spatial visualizations for communicating climate change risks. Geomatica, 66(1), 255-265.

doi.org/10.5623/cig2012-006.

Macchione, F., Costabile, P., Costanzo, C., Santis, R. D., 2019: Moving to 3-D flood hazard maps for enhancing risk communication. Environmental Modelling \& Software, 111, 510-522. doi.org/10.1016/j.envsoft.2018.11.005.

Maidl, E., Buchecker, M., 2014: Raising risk preparedness through flood risk communication. Natural Hazards and Earth
System Sciences Discussions, 15(7), 1577-1595. doi.org/10.5194/nhess-15-1577-2015.

Markwart, H., Vitera, J., Lemanski, S., Kietzmann, D., Brasch, M., Schmidt, S., 2019: Warning messages to modify safety behavior during crisis situations: A virtual reality study. International Journal of Disaster Risk Reduction,38, 101235. doi.org/10.1016/j.ijdrr.2019.101235.

Marx, S. M., Weber, E. U., Orlove, B. S., Leiserowitz, A., Krantz, D.H., Roncoli, C., Phillips, J., 2007: Communication and mental processes: Experiential and analytic processing of uncertain climate information. Global Environmental Change, 17(1), 47-58. doi.org/10.1016/j.gloenvcha.2006.10.004.

Merién, A.E., van de Ven, J., Mol, B.W., Houterman, S., Oei, S.G., 2011: Multidisciplinary Team Training in a Simulation Setting for Acute Obstetric Emergencies. Obstetric Anesthesia Digest, $31(2)$ 83-84. doi.org10.1097/01.aoa.0000397113.95428.cb.

Mitchell, J.T., Cutter, S.L., 1997: Global Change and Environmental Hazards: Is the World Becoming More Disastrous? Hands-On! Developing Active Learning Modules on the Human Dimensions of Global Change. Association of American Geographers, Washington, DC, USA.

Morrow, B. H., Lazo, J. K., Rhome, J., Feyen, J., 2015: Improving storm surge risk communication: Stakeholder perspectives. Bulletin of the American Meteorological Society, 96(1), 35-48. doi.org/10.1175/BAMS-D-13-00197.1.

Moulon, P., Monasse, P., Marlet, R., and others, 2016: openMVG. GitHub. https://github.com/openMVG/openMVG.

Oculus, 2020: Oculus | VR Headsets \& Equipment. https://www.oculus.com/.

Orland, K., Ars Technica, 2014. Facebook purchases VR headset maker Oculus for \$2 billion. https://arstechnica.com/gaming/2014/03/facebook-purchases-vrheadset-maker-oculus-for-2-billion/ (25 March 2014).

Petty, R. E., Cacioppo, J.T., 1984: Source factors and the elaboration likelihood model of persuasion. Advances in Consumer Research, 11, 668-672. https://www.acrwebsite.org/volumes/6328/volumes/v11/NA11.

Petty, R.E., Cacioppo, J.T., 1986: Communication and Persuasion: Central and Peripheral Routes to Attitude Change. Springer-Verlag New York.

Regard3D, 2020: Regard3D, a free and open source structurefrom-motion-program. Version 1.0.0.https://www.regard3d.org/ (14 March 2019).

Rossol, N., Cheng, I., Bischof, W. F., Basu, A., 2011: A framework for adaptive training and games in virtual reality rehabilitation environments. Proceedings of the 10th International Conference on Virtual Reality Continuum and Its Applications in Industry - VRCAI 11. doi.org/10.1145/2087756.2087810.

Russell, J. A., Ward, L. M., Pratt, G. 1982: Affective Quality Attributed to Environments: A Factor Analytic 
Study. Environment and Behavior, 13(3), 259-288.

doi.org/10.1177/0013916581133001.

Schuetz, M., and others, 2020a: potree. GitHub.

https://github.com/potree/potree.

Schuetz, M., and others, 2020b: PotreeConverter. Github. https://github.com/potree/PotreeConverter.

Shuman, S., Playstation Blog, 2019: PlayStation VR: The Next Wave of Games Coming in Spring and Summer 2019. blog.us.playstation.com/2019/03/25/playstation-vr-the-nextwave-of-games-coming-in-spring-and-summer-2019/ (26 March 2019).

Schuurink, E. L., Toet, A., 2010: Effects of Third Person Perspective on Affective Appraisal and Engagement: Findings from SECOND LIFE. Simulation \& Gaming, 41(5), 724-742. doi.org/10.1177/1046878110365515.

Sharma, U., Patwardhan, A., Patt, A.G., 2013: Education as a determinant of response to cyclone warnings: Evidence from coastal zones in India. Ecology and Society, 18(2), 18. doi.org/10.5751/ES-05439-180218.

Solinska-Nowak, A., Magnuszewski, P., Curl, M., French, A., Keating, A., Mochizuki, J., . . . Jarzabek, L., 2018: An overview of serious games for disaster risk management - Prospects and limitations for informing actions to arrest increasing risk. International Journal of Disaster Risk Reduction, 31, 1013-1029. doi.org/10.1016/j.ijdrr.2018.09.001.

Turk, G., 1994: Polygon File Format (PLY) Family. Digital Preservation at the Library of Congress.

https://www.loc.gov/preservation/digital/formats/fdd/fdd000501 .shtml (2019).

Vasileiadou, E., Botzen, W.J.W., 2014: Communicating adaptation with emotions: The role of intense experiences in raising concern about extreme weather. Ecology and Society, 19(2), 36. doi.org/10.5751/ES-06474-190236.

Velev, D., Zlateva, P., 2017: Virtual Reality Challenges in Education and Training. International Journal of Learning and Teaching, 3(1). doi.org/10.18178/ijlt.3.1.33-37.

Virtual Reality Society, 2017. History Of Virtual Reality. https://www.vrs.org.uk/virtual-reality/history.html (26 March 2019).

Wang, C., Hou, J., Miller, D., Brown, I., Jiang, Y., 2019: Flood risk management in sponge cities: The role of integrated simulation and 3D visualization. International Journal of Disaster Risk Reduction, 39, 101139. doi.org/10.1016/j.ijdrr.2019.101139. 